\title{
Flexible Plate Teeth Type Sugarcane Leaf-Stripping Device
}

\author{
Xin Jin, Xinwu Du, Dongyang Wang, Weixiang Liu and Jiangtao Ji \\ College of Agricultural Engineering, Henan University of Science and Technology \\ Henan Luo Yang, 471003, China \\ jjt0907@163.com
}

\begin{abstract}
In sugarcane combine harvesting, not hulling rate and damage rate of sugarcane in the process of leaf stripping are rather high. Thus, multiple flexible leaf stripping system was" proposed. Making using of general multiple flexible leaves stripping to sigarcane, leaf-stripping device with flexible plate teeth was developed. On the basis of the four-factor second order rotation combination experiment, a neural network prediction model between working performance influence factor and indêx was established. And according to using BP neural network and Genetic Algoxithm, the facility parameter optimization was performed. The best parameter combination for the facility was the rotational speed of inlet roller $623.2 \mathrm{r} / \mathrm{min}$, the rotational speed of first order leaf-stripping roller $951.6 \mathrm{r} / \mathrm{min}$, the rotational speed of second order leaf stripping roller $1129.4 \mathrm{r} / \mathrm{min}$, the rotational speed of deliver roller 846.7rmin. The resulls show that a new approach for performance prediction model building and parameter optimization of sugarcane leaf-stripping device with flexible platecteeth, combining BP neural network with Genetic Algorithm is reliable, accurate and féasible.
\end{abstract}

Keywords: Sugarcane, Leaf-stripping device, Flexible plate teeth, BP neural network, parameter optimization

\section{Introduction}

Leaf-stripping is an impotant link in process of sugarcane harvest, and the performance of leaf-stripping device of sugarcane harvester directly affects the final quality of pressing sugarcanes[1]. So far, a lot of theoretical and testing researches for mode and mechanism of leaf-stripping, performance and material of cleaning elements etc. had been done by donestic and foreign experts[2-14].

There are three kinds of leaf-stripping device used in existing sugarcane harvesters, which contains rubber-finger-drum style, steel-wire-drum style, and airstream style[2]. Moreover, these modes remove leaves from sugarcane stalk respectively by blow force of rubber ingers and friction force between rubber fingers and the stalk among them, friction force between steel wires and sugarcane leaves, and airflow action of high speed and high pressure. It is reported that there were still some problems in those leaf-stripping devices, such as easily damaged of stalks, short life of cleaning elements or high not hulling rate[2-6]. Therefore, this study designed a sugarcane leaf-stripping device with flexible plate teeth, meanwhile built the performance prediction model of this device, and then performed the parameter optimization of it.

\section{Structure and Working Principle}

\subsection{Structure of Leaf-Stripping Device}

The leaf-stripping device with flexible plate teeth mainly composed by frame, cleaning 
elements, four pairs of drums with adjustable gap, as shown in Figure 1. In order to ensure matching ability between this device and sugarcane harvester, meanwhile uniformly forced in leaf-stripping process and little injury of the stalk, the leaf-stripping drums were symmetrically distributed upper and lower (drums with cleaning elements were called leaf-stripping rollers while with the same direction and equal rotational speed). Moreover, the main parameters of this device were determined such as inlet roller diameter of $260 \mathrm{~mm}$, other rollers diameter of $270 \mathrm{~mm}$, transverse space between the adjacent two groups of leaf-stripping roller of $500 \mathrm{~mm}$, and angle between the device axis and ground of $16^{\circ}$. In addition, the cleaning elements with flexible plate teeth were shown in Figure 2, and the material of them was wear resistant rubber. Furthermore, four and six pieces of cleaning elements were respectively uniformly distributed in inlet roller and other rollers.

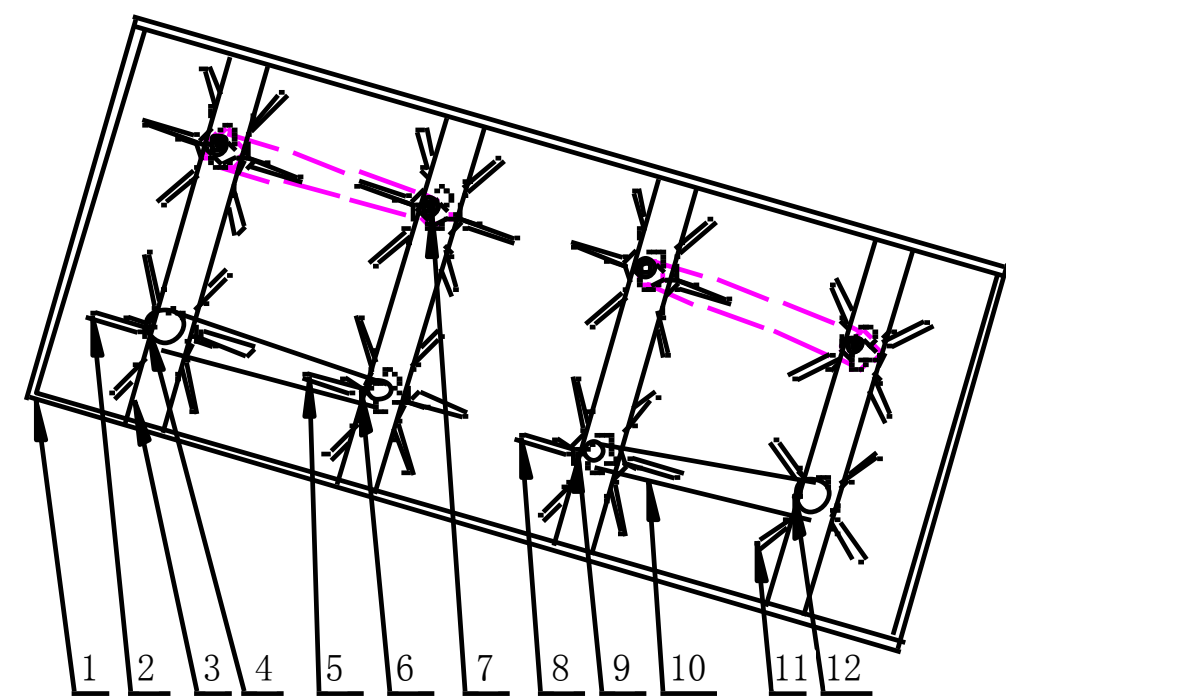

1,3. Frame 2,5,8. Cleaning element 4. Deliver roller 6 . Second order leaf- stripping roller 7. Bearing chock 9 First order leaf-stripping roller 10. Transmission chain 11. Cleaning element II 12. Inlet roller

\section{Figure 1. Test Device of Sugarcane Leaf-Stripping with Flexible Plate Teeth}

In Figure 2, cleaning element of No. 1 was used in inlet roller; the average diameter of sugarcanes was $28 \pm 4 \mathrm{~mm}$ by test measurement. In order to grasp and feed the sugarcanes favorably, the minimum leaf-stripping clearance of inlet roller was taken as $20 \mathrm{~mm}$. Further, a flexible are teeth design was adopted for cleaning element of No. I . Cleaning element of No. IN was used in other rollers, and a flexibly rectangular plate teeth design was adopted for it. So this design is more active for attack and friction effect of sugarcanes. Meanwhile, for reducing the injury of sugarcane stalks, the leaf-stripping clearanoe of other rollers was taken as $25 \mathrm{~mm}$. 


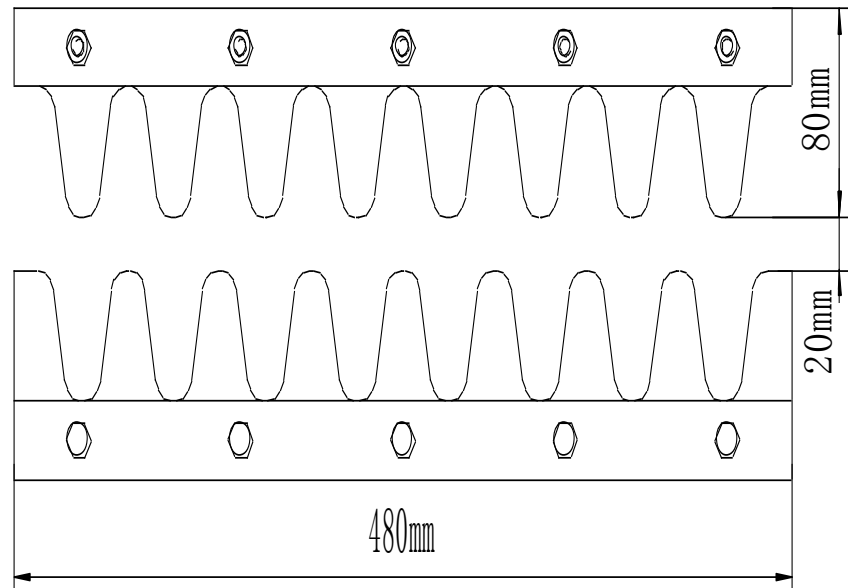

(a) Cleaning element I

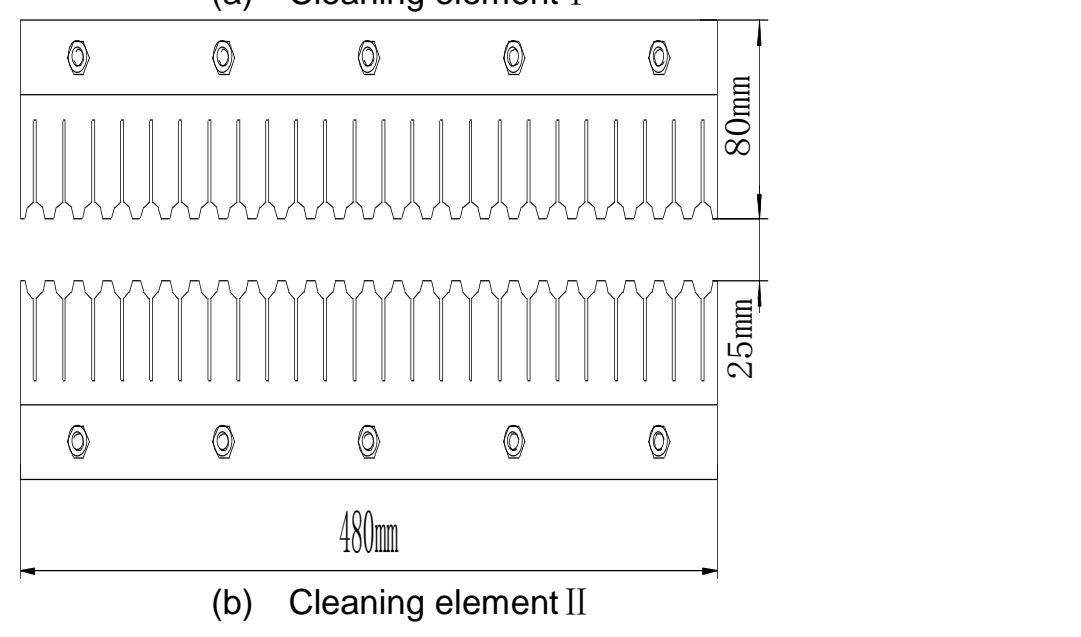

PFigure 2. Cleaning Elements

\subsection{Working Principle}

In working process, with lear-stripping rollers rotating, the cleaning elements made uniform circular motion with different speeds. When the root of sugarcane was touched with cleaning elements of Inlet roller, it was immediately hit and extruded into the device. Furthermore, upper and lower cleaning elements made intimate contact of leaves and stalks then prodicing a certain pressure. So, the sugarcanes were successfully fed. Subsequently, the sugarcanes continued by crossing first order leaf-stripping roller, second ofder leaf-stripping roller and deliver roller, meanwhile repetitive hit, extrusion and friction of leaves and stalks were realized. Then the stalks and loose leaves were thrown out from the device, and separated by their self-weight.

\section{Establishment of Performance Prediction Model of the Device}

The main performance influence factors of leaf-stripping device with flexible plate teeth were determined: the rotational speed of inlet roller $\mathrm{x} 1$, the rotational speed of first order leaf-stripping roller $\mathrm{x} 2$, the rotational speed of second order leaf-stripping roller $\mathrm{x} 3$, the rotational speed of deliver roller $\mathrm{x} 4$. The test indexes were not hulling rate $\mathrm{y} 1$ and damage rate of sugarcanes y 2 which were taken by sugar manufactured enterprises to measure the quality of pressing sugarcanes. In addition, the training data of BP network was constructed by using four-factor second order rotation combination experiment.

The test material was natural maturity sugarcanes Tai Tang 22 in the same year. The average height was $2000 \pm 18 \mathrm{~mm}$, the average diameter was $28 \pm 4 \mathrm{~mm}$, the moisture content 
of sugarcane leaves was $23 \%$, and the leaf stem ratio was $7.2 \%$. The sugarcanes feeding were used by the belt device for simulating the sugarcane harvester working, and the feed rate was $2.8 \mathrm{~kg} / \mathrm{s}$. The test times were 31 , then after every time the quality of loose leaves, residual leaves, injured stalks, and total stalks were respectively weighed. Furthermore, the test index value was obtained. So, factors and levels of the experiment was illustrated in Table 1, meanwhile the test scheme and prediction results as shown in Table 2.

Table 1. Factors and Levels of Experiment

\begin{tabular}{ccccc}
\hline Level code & $x_{1} / \mathrm{r} / \mathrm{min}$ & $x_{2} / \mathrm{r} / \mathrm{min}$ & $x_{3} / \mathrm{r} / \mathrm{min}$ & $x_{4} / \mathrm{r} / \mathrm{min}$ \\
\hline Upper asterisk arm (+2) & 900 & 1000 & 1150 & 1150 \\
Upper level (+1) & 812.5 & 912.5 & 1062.5 & 1037.5 \\
Zero level (0) & 725 & 825 & 975 & 925 \\
Lower level (-1) & 637.5 & 737.5 & 887.5 & 812.5 \\
Lower asterisk arm (-2) & 550 & 650 & 800 & 700 \\
Constant intervals $\Delta \mathrm{j}$ & 87.5 & 87.5 & 87.5 & 112.5 \\
\hline
\end{tabular}

\subsection{Implementation of BP Network Prediction Model}

The test conditions and results were taken as input-oltput pattern pairs of BP network, after normalization processing of input vector, the final structure parameters of BP network were confirmed by contrastive experiments the unit number of input layer, single hidden layer and output layer respectively was 4,6 , and 2.Further, the structure of BP network prediction model for this study was shown in Figure 3. Then, we selected the learning coefficient of 0.05 , the momentumcoefficient of 0.8 , and the global error of 0.00004 , through the iteration of 20 times, the error function tended to be stable, as shown in Figure 4. The final learning outcome was illustrated in Table 2, which No.11, 13, 15 were the output of prediction test sample.

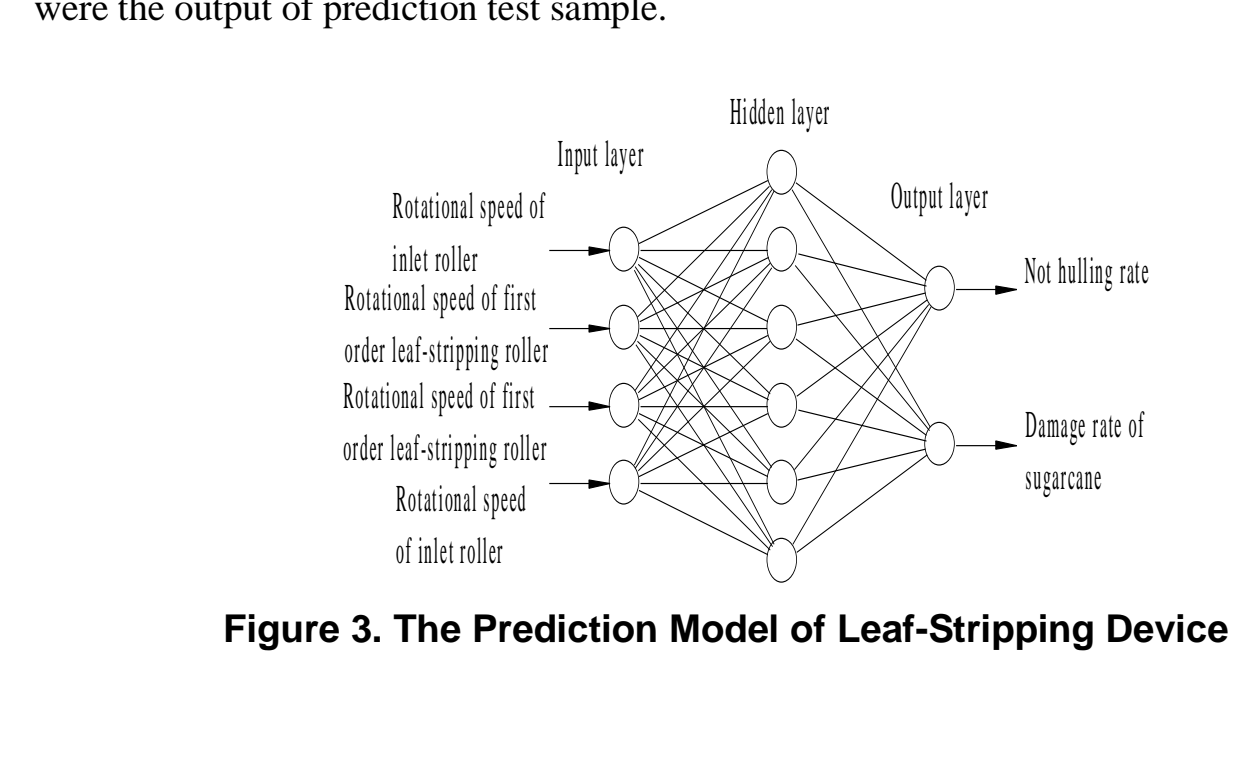




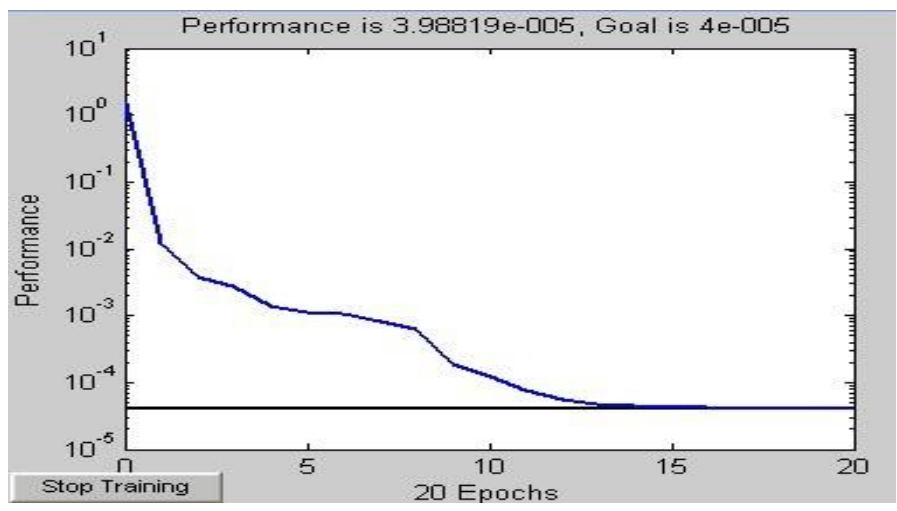

Figure 4. BP Neural Network Training Error

\subsection{Analysis of Prediction Results}

After the network training was finished, through using the simfunction, the test data of prediction test sample No.11, 13, 15 which randomly selected were inputted into it for simulation test. The relative error between prediction results and measured values of not hulling rate and stalks damage rate was illustrated in Table 3.

Table 2. Four-Factor Second Order Rotation Combination Experiment and Results

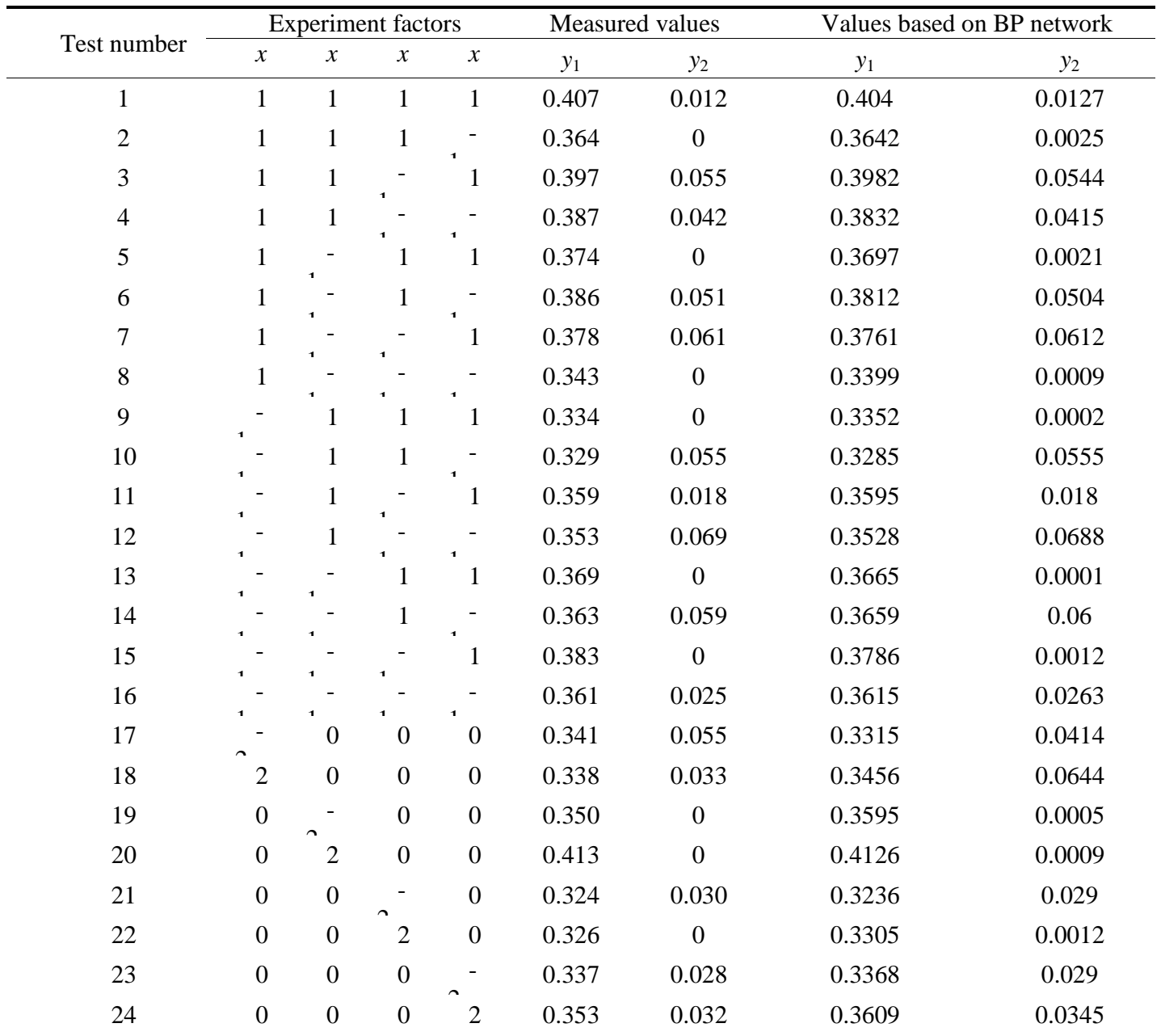




\begin{tabular}{llllllcll}
25 & 0 & 0 & 0 & 0 & 0.335 & 0 & 0.3387 & 0.02 \\
26 & 0 & 0 & 0 & 0 & 0.348 & 0.038 & 0.3387 & 0.02 \\
27 & 0 & 0 & 0 & 0 & 0.346 & 0.02 & 0.3387 & 0.02 \\
28 & 0 & 0 & 0 & 0 & 0.335 & 0.016 & 0.3387 & 0.02 \\
29 & 0 & 0 & 0 & 0 & 0.329 & 0 & 0.3387 & 0.02 \\
30 & 0 & 0 & 0 & 0 & 0.331 & 0.046 & 0.3387 & 0.02 \\
31 & 0 & 0 & 0 & 0 & 0.342 & 0.019 & 0.3387 & 0.02 \\
\hline
\end{tabular}

Table 3. Error of Prediction Results of BP Neural Network Model

\begin{tabular}{ccc}
\hline \multirow{2}{*}{$\begin{array}{c}\text { Test number of forecast } \\
\text { sample }\end{array}$} & \multicolumn{2}{c}{ Based on BP network } \\
\cline { 2 - 3 } & $\begin{array}{c}\text { Relative error of not hulling } \\
\text { rate/\% }\end{array}$ & $\begin{array}{c}\text { Relative error of damage rate of } \\
\text { sugarcane/\% }\end{array}$ \\
11 & 0.14 & 0 \\
13 & 0.68 & 0.01 \\
\hline
\end{tabular}

Data in Table 3 shows that the prediction error of BR network prediction model was less. Therefore, the performance prediction model of leaf-stripping device with flexible plate teeth was effective.

\section{Parameter Optimization Analysis}

\subsection{Parameter Optimization for Prediction Model Based on Genetic Algorithm}

The simulation results of BP network model namely sim(net, y) were taken as fitness function, because of the outpat $y=\left\{y_{y_{2}}\right\}^{1}$ of two-dimensional, the corresponding dimension was used as each sub-objective function. Let initial population size be 200, namely each sub-population size was 100 ; employed the binary system coding; set the selected function of rancom ergodic sampling (sus); the crossover operator was alone point crossing (xoysp) and its probability was 0.8 ; the mutation operator was discrete mutation (mut) and its probability vas 0.005; the iterative number was 50, and the searching range of variables was the range which after normalization processing of input parameters from test sample.

Finally, through using the genetic algorithm toolbox which developed by Sheffield University based on MATLAB [15], the programming operational was carried out. When the iteration closed to 50th generation, each sub-goal value tended to be stable.

The output results of parameters optimization were as following: not hulling rate of sugarcanes $\mathrm{y} 1=29.45 \%$, and damage rate of sugarcane stalks $\mathrm{y} 2=1.52 \%$; the corresponding parameters after inverse normalizing were that the rotational speed of inlet roller $632.2 \mathrm{r} / \mathrm{min}$, the rotational speed of first order leaf-stripping roller $951.6 \mathrm{r} / \mathrm{min}$, the rotat onal speed of second order leaf stripping roller $1129.4 \mathrm{r} / \mathrm{min}$, the rotational speed of deliver roller $846.7 \mathrm{r} / \mathrm{min}$.

\subsection{Verification Analysis of Optimization Results}

In order to prove the reliability of the optimization results, we completed the verifying test by using the same batch of sugarcanes. The sugarcanes after test were shown in Figure 5 . 


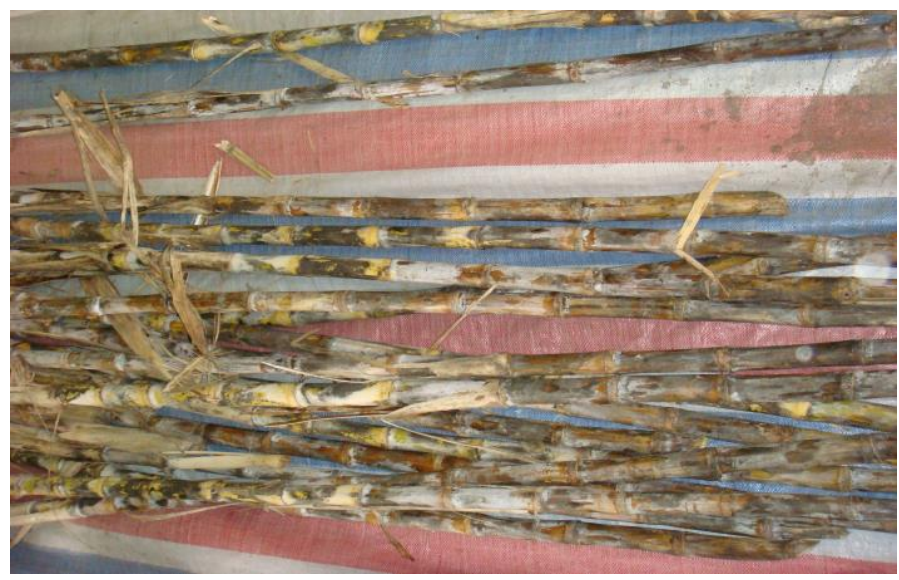

Figure 5. The Sugarcanes after Test

The results of verifying test were illustrated in Table 4.

Table 4. Experimental Scheme and Results for Prediction Verification

\begin{tabular}{|c|c|c|c|c|c|}
\hline \multirow[b]{2}{*}{ Test number } & \multirow{2}{*}{\multicolumn{3}{|c|}{ Test schenie }} & \multicolumn{2}{|c|}{ Results } \\
\hline & & & & $y_{1} / \%$ & $y_{2} / \%$ \\
\hline Optimal values & 623.2 & & 46.7 & $\begin{array}{l}29.4 \\
5\end{array}$ & 1.52 \\
\hline Verification 1 & 623 & & 845 & $\begin{array}{l}30.1 \\
3\end{array}$ & 1.45 \\
\hline Verification 2 & & & 844 & $\begin{array}{l}29.5 \\
6\end{array}$ & 1.62 \\
\hline Verification 3 & 62 & & 847.5 & $\begin{array}{l}28.8 \\
9\end{array}$ & 1.50 \\
\hline
\end{tabular}

It was shown that the predictive values were quite closed to test results, so this performance prediction and optimization model established by BP network combined with Genetic Algorithm waspeliable and practical.

\section{Conclusions}

A sugarcane eafstripping device with flexible plate teeth was designed, which principal working parts were four pairs of rollers with adjustable gap, as well as cleaning elements with flexible plate teeth.

The BP network prediction model for forecasting the performance of this device was established; meanwhile the performance prediction results for this device were accurate ancredible.

The optimum parameter combination of this device was that: the rotational speed of inlet roller was $632.2 \mathrm{r} / \mathrm{min}$, the rotational speed of first order leaf-stripping roller was $951.6 \mathrm{r} / \mathrm{min}$, the rotational speed of second order leaf stripping roller was $1129.4 \mathrm{r} / \mathrm{min}$, and the rotational speed of deliver roller was $846.7 \mathrm{r} / \mathrm{min}$. Under this parameter combination, through test verifying, the average not hulling rate was $29.5 \%$, and the average damage rate of sugarcane was $1.52 \%$. 


\section{Acknowledgement}

This work was supported by Henan scientific and technological research projects (No. 20100030502) and the Youth Science Funds of Henan University of Science \&Technology (No.2015QN004).

\section{References}

[1] F. L. Ma, "Virtual experimental analysis on the cleaning element in brush shape of sugarcane harvester", Nanning: Guangxi University, (2002).

[2] L. N. ShuKla, "Design Development and Testing of Sugarcane cleaner", American society of Agricultural Engineers, vol. 22, (1991), pp. 51-56.

[3] Srivastava, "Development of a power driven sugarcane detrasher", Agricultural Mechanization in Asia, Africa and Latin American, vol. 21, (1990), pp. 49-52.

[4] Y. M. Meng, Y. L. Chen, and S. P. Li, "Research on the orthogonal experiment of numeric simulation of macromolecule-cleaning element for sugarcane harvester", Materials and Design, vol. 30, (2009), pp. 2250-2258,

[5] Y. M. Meng, S. P. Li, and Z. S. Liu, "Research on a kind of optimum design method for cleaning element of sugarcane harvester", Journal of China Mechanical Engineering, vol. 14, (2003), pp. 901-904.

[6] L. L. Huang, "Experimental Research on Factors Affecting the Detrashing quality of the Sugarcane detrasher", Nanning: Guangxi University, (2008).

[7] S. P. Li, Y. M. Meng and F. L. Ma, "Research on the working mechanism and virtual testing for cleaning element in brush shape of the sugarcane haryester", Joumal of Material Processing Technology, vol. 129, (2002), pp.418-422.

[8] J. Yang, Z. X. Liang, and J. L. Mo, "Experimentaresearch on factors affecting the cutting quality of sugarcane cutter", Transactions of the CSAE, vol. 21 (2005), pp. $60-6$.

[9] H. Q. Shang and Y. G. Qu, "Application of computer image technology on principle of sugarcane detrashing”, Journal of South China Agricyltural University, vol. 21, (2000), pp. 81-84.

[10] R. Huang, S. Liang, and L. Shan, "The helical arrangement of sugarcane's leaf cleaning components", Journal of Agricultural Mechanization Research, vol. 4, (2007), pp. 99-101.

[11] X. Lai, S. Liang, and L. L. Du, "Analysis on helical arrangement of sugarcane cleaning components based on ADAMS", Journal of Agticultural Mechanization Research, (2008), pp.23-27.

[12] G. J. Wang, J. Yang, and Z. X. Liang, "Experment study of the factors influence on the sugarcane detrashing quality of sugarcane detrashing machine", Journal of Agricultural Mechanization Research, vol. 12, (2006), pp. 142-145

[13] S. P. Li, Y. M. Mêng, andF. L. Ma, "Virtual experiment analysis of brush shape of cleaning element for sugarcane harvester", Transactions of the Chinese Society for Agricultural Machinery, vol. 34, (2003), pp. 43-46.

[14] S. P. Li F. M Ma, and Y L. He, "Performance analysis on cleaning element of sugarcane harvester based on neural network", Transactions of the Chinese Society for Agricultural Machinery, vol. 37, (2006), PP. 69-73.

[15]G. Gao and J. S. Lue, Estimating kinetic parameters of Chemical and biochemical reaction with general genetic algorithp" Conputers and Applied Chemistry, vol. 22, (2005), pp.916-917.

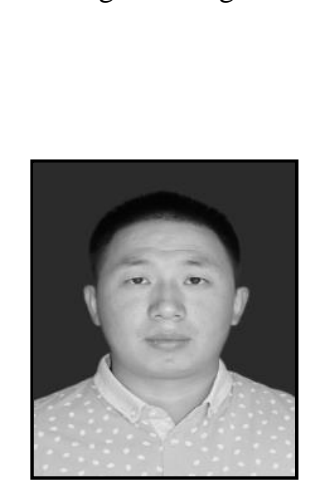

\section{Authors}

Xin Jin, he received his Ph.D. degree in the China Agricultural University, in 2014. His current research interests include the intelligent agricultural equipment. 


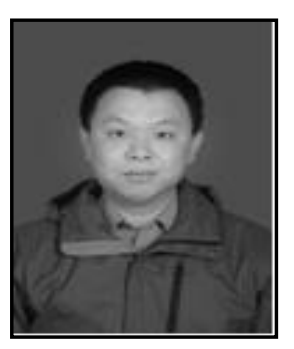

Xinwu Du, he received his Ph.D. degree in the Beijing Institute of Technology, in 2009. His current research interests include the intelligent agricultural equipment.

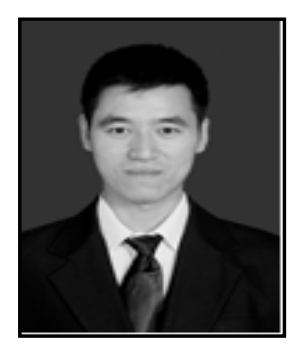

Dongyang Wang, he received his master degree in the Henan University of Science and Technology, in 2014. His current research interests include the intelligent agricultural equipment.

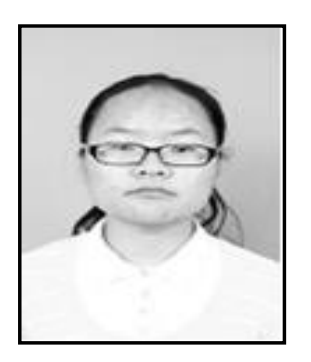

Weixiang Liu, she received her master degree in the Henan University of Science and Technology, in 2014. Her current research interests include the intelligent agricultural equipment.

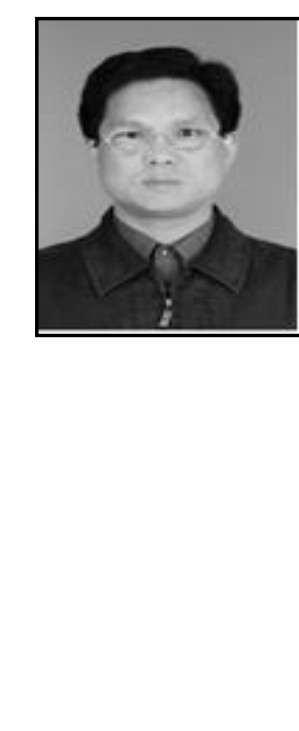

Jiangta Ji, he received his Ph.D. degree in the Beijing Institute of Technology, in 2007. His current research interests include the inteligent agricultural equipment. 
International Journal of Hybrid Information Technology Vol. 9, No.9 (2016)

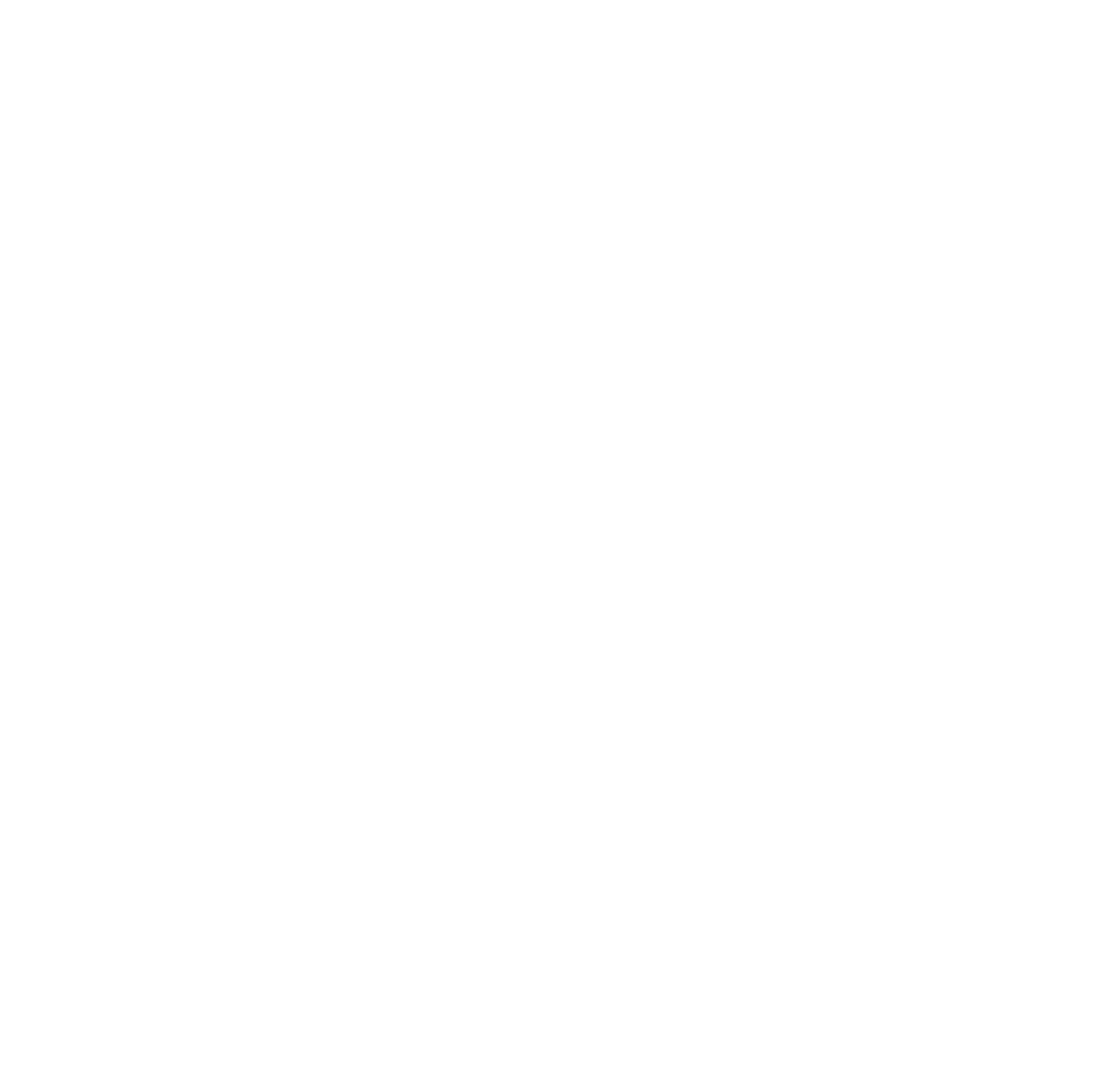

